IZA DP No. 9762

The Formation of Networks in the Diaspora

Gil S. Epstein

Odelia Heizler (Cohen)

February 2016 


\title{
The Formation of Networks in the Diaspora
}

\author{
Gil S. Epstein \\ Bar-Ilan University, \\ CReAM and IZA \\ Odelia Heizler (Cohen) \\ Tel-Aviv-Yaffo Academic College \\ and IZA \\ Discussion Paper No. 9762 \\ February 2016 \\ IZA \\ P.O. Box 7240 \\ 53072 Bonn \\ Germany \\ Phone: +49-228-3894-0 \\ Fax: +49-228-3894-180 \\ E-mail: iza@iza.org
}

\begin{abstract}
Any opinions expressed here are those of the author(s) and not those of IZA. Research published in this series may include views on policy, but the institute itself takes no institutional policy positions. The IZA research network is committed to the IZA Guiding Principles of Research Integrity.

The Institute for the Study of Labor (IZA) in Bonn is a local and virtual international research center and a place of communication between science, politics and business. IZA is an independent nonprofit organization supported by Deutsche Post Foundation. The center is associated with the University of Bonn and offers a stimulating research environment through its international network, workshops and conferences, data service, project support, research visits and doctoral program. IZA engages in (i) original and internationally competitive research in all fields of labor economics, (ii) development of policy concepts, and (iii) dissemination of research results and concepts to the interested public.
\end{abstract}

IZA Discussion Papers often represent preliminary work and are circulated to encourage discussion. Citation of such a paper should account for its provisional character. A revised version may be available directly from the author. 
IZA Discussion Paper No. 9762

February 2016

\section{ABSTRACT \\ The Formation of Networks in the Diaspora}

In this paper, we examine possible types of network formation among immigrants in the diaspora and between those immigrants and the locals in different countries. We present the model by considering different possible interactions between immigrants and the new society in their host country. Spread of migrants from the same origin in the diaspora may well increase international trade between the different countries, depending on the types of networks formed. We present possible applications of network structure on the country of origin, such as on international trade. We find that when the size of the diaspora is sufficiently large, the natives in the different countries will be willing to bear the linking cost with the immigrants because the possible benefits increase with increasing size of the diaspora.

JEL Classification: D85, D74, J61, L14

Keywords: immigrants, networks, diaspora

Corresponding author:

Gil. S. Epstein

Department of Economics

Bar-Ilan University

52900, Ramat-Gan

Israel

E-mail: gil.epstein@biu.ac.il 


\section{Introduction}

"Diaspora" is derived from two Greek words meaning "a scattering or sowing of seeds" and refers to the displacement or dispersion of members of an ethnic group from their country of origin to foreign lands. The diaspora is defined as people who have migrated away from their homelands, as well as their descendents, but who maintain a connection to their home country (see Plaza, 2013). Examples of a diaspora are the Jews who were exiled from Israel, the Mexican diaspora in the United States, the Turkish diaspora in Germany, and the Indian and African diasporas in all major regions of the world.

The diaspora contributes not only to the immigrants in the diaspora, but possibly also to their source and destination countries. When immigrants settle in a host country, they need social support, job-search assistance, help in finding accommodations or temporary lodging, and information regarding the alien environment and local culture. Settling in ethnic concentrations supplies those needs and decreases the migration cost (see, for example, Carrington et al., 1996).

The source country benefits from the diaspora in several ways. The first is diaspora remittances. The migrants pay allegiance to their home countries by repatriating funds to support various activities. This includes gifts to family members meant to bring about the family's development, paying school fees, building houses and structures of all kinds, and growing businesses. Bodomo (2013) indicated that diaspora remittances are better than foreign aid that is not received from the diaspora. This is because remittances go directly to their targets, in contrast to foreign aid funds which have been known to be misappropriated at governmental and nongovernmental levels. Using data on the Central African diaspora, Tchouassi and Sikod (2010) found that recent migrants in the diaspora are motivated by the need to support families back home. However, the first migrants are motivated largely by altruism, charity, and in today's globalization, a desire to bridge the developmental divide. Hercowitz and Pines (1997) showed that the Jewish diaspora is increasing its donations to Israel as the number of immigrants to Israel increases.

The second benefit to the home country, as well as to the host country, is international trade. Numerous studies have shown that immigrants affect bilateral trade, for example, a $10 \%$ increase in immigrants to the United States (US) will 
increase US exports to the country of origin by $4.7 \%$ and US imports from the country of origin by $8.3 \%$ (see for survey, Rauch, 2001).

In addition to funds, the migrants who work in and are familiar with the host country typically provide business contacts, and knowledge of home-country market sources, laws and regulations, and of differences in culture and in ways of doing business. Immigrants can have an advantage in dealing with their countrymen who remain in the home country due to issues of trust or mutually understood culture. In addition, cultural ties, such as common languages, historical colonial ties, common preferences, and the knowledge of political and social institutions, can reduce trading transaction costs and facilitate an exporter's entry into the foreign market (Casella and Rauch, 2002). Moreover, the trust produced within the networks may facilitate the flow of financial capital as well as goods between network members. Immigrants can serve as a bridge between the host countries and their countries of origin (Blanes, 2005; Epstein and Heizler, 2009).

Third, migrants may help overcome informational barriers to direct foreign investments and thus increase the attractiveness of the home country to potential foreign investors. This may be interpreted as a reduction in the country-risk premium required to invest in the country of origin. Kugler and Rapoport (2007) found that a $1 \%$ increase in the stock of migrants with tertiary education residing in the United States in 1990 was associated with a $1.1 \%$ rise in the annual growth rate of direct foreign investment inflow throughout the period covered.

Fourth, the diaspora has a central role in the transfer of knowledge, technology and innovation to different countries worldwide. Return migration and cross-border diaspora networks promote access to foreign-produced knowledge and foster innovation by encouraging trade, investments and the recirculation of information back into the source countries. Naghavi and Strozzi (2015) showed a positive correlation between emigration and innovation in the presence of strong intellectual property rights protection.

Finally, the diaspora may decrease the visa costs for future immigrants. Many destination countries have specific programs for family reunification or for highly skilled individuals. An immigrant (who arrived with a student visa for example) who marries a local can become eligible to sponsor a visa for his/her closest relatives, regardless of their skills. Using data from 30 OECD countries, Beine et al. (2011) 
found that the diaspora increases migration flow and lowers the migrants' average educational level.

In this paper, we present a model of immigrant network formation in the diaspora. The fact that the migrants are all from the same origin increases the chances of knowledge moving from one to the other and enables trade channels between the different countries of the diaspora to which the migrants have emigrated.

Numerous studies have shown that immigrants tend to settle in ethnic concentrations (see, for example, Bartel, 1989; Carrington et al., 1996; Borjas, 2000; Bauer et al., 2005). As already noted, the immigrant arriving in the host country needs social support, job-search assistance, help in finding accommodations or temporary lodging, and information regarding the alien environment and the local culture. The immigrant can invest effort in the assimilation, such as acquiring the local language, and can obtain assistance from natives, or he or she can acquire such information from previous immigrants (see Epstein and Gang, 2010). These type of networks also increase the relationship between the local population and the migrants from a certain location of origin in the diaspora.

One important element of creating a diaspora network is assimilation of the migrant in a local residence. Although at first, residence in ethnic concentrations facilitates the assimilation process, studies have shown that it may have a negative effect on the success of the adjustment. For example, Culter and Gleaser (1997) found that blacks who are located in more segregated areas have significantly less success in schooling, employment and single parenthood than those in less segregated areas. Borjas (2000) found that residential segregation of ethnic groups hampers the process of economic assimilation. The reason for this negative effect is that an increase in the immigrants' stock in the enclaves increases the competition for jobs and decreases the immigrants' wages (see Bauer et al., 2007). Furthermore, these enclaves create incentives for the immigrants not to acquire the culture and language of the host country. A destination language deficiency reduces income and hampers assimilation (see, for example, Chiswick, 1978). Moreover, the existence of an ethnic enclave may create xenophobia (see, for example, Dustmann and Preston, 2007).

In general, there are four possible states of interaction between the immigrant and his/her host and home societies (or ethnic identification) (Berry, 1997): 
assimilation is achieved when the immigrants have a strong interaction with the host society but not with the home society; separation occurs when the immigrants have a strong interaction with the home society but not with the host society; integration occurs when the immigrants interact with both societies, and marginalization occurs when the immigrants have no interaction with either society. These are all very important for the creation of the diaspora network, because they determine the type of connection that is created locally.

There is an emerging body of literature examining the assimilation of immigrants in terms of different migrant characteristics, such as age at arrival, gender, education and religion. For example, using unique data from Germany, Constant et al. (2009) found that young immigrants assimilate or integrate. Constant et al. (2006) found that Muslim women integrate and assimilate less, and are more segregated than Muslim men, whereas there are no differences between Christian men and women. Constant and Zimmermann $(2009,2013)$ showed that the state of ethnic identification is an important factor in labor force participation, with separation and marginalization decreasing the probability of immigrants being employed. ${ }^{1}$ Comola and Mendola (2015) performed an empirical examination of network formation among immigrants in a host society using data of Sri Lankans who settled in Milan. They found that migrants tended to interact with co-nationals who came from nearby locales in Sri Lanka and had arrived in Italy either at the same time as, or long before them. A Ushaped curve was found to describe the relationship between the difference in times of arrival and the probability of forming links, with the turning point at about 20 years difference between arrival times.

The current paper adds to the extant literature by examining the process underlying the formation of each of these states of ethnic identification (i.e., assimilation, segregation, integration and marginalization) and connects it to the diaspora networks. We present the conditions for each of the different possible states in terms of adjustment costs and immigrant utility obtained from the relationship with the native inhabitants.

In this paper, we present a new approach to describing the immigrants' social network, using a network-formation method. The network-formation literature

\footnotetext{
${ }^{1}$ There may also be political economy issues. On this topic, see Epstein (2013).
} 
presents possible connections between agents, with the agents being the nodes in the structure. ${ }^{2}$ We apply this type of formation between immigrants and natives with the necessary modifications. For example, when an immigrant creates a linkage with the natives, he or she has a fixed adjustment cost, in addition to the direct linking cost. Moreover, the benefit to the immigrant and the native from the interaction is not symmetrical: the immigrant can derive more benefit from the linkage than the native (at least in the short run, on which we focus). We highlight the creation of immigrant leadership, which is used as a middleman between the immigrants and the natives. Immigrant leadership might affect the migrants' relationships throughout the diaspora, among themselves and with their source country.

The paper is organized as follows. Section 2 presents the model of network formation among immigrants and natives. In Section 3, we determine who incurs the linkage costs between immigrants and natives. Section 4 concludes.

\section{Network formation among immigrants and natives}

Suppose a society of natives exists where, in each period, a new immigrant joins that society. The new immigrant decides with whom to form a link (only with natives, only with immigrants, or with immigrants and natives), with each linkage costing $e$ in terms of time, effort and/or money. Immigrants speak different languages and have different customs than the natives, hence when the linkages are formed between immigrants and natives, there is an adjustment cost $c$, in addition to the variable linking cost ( $e$ multiplied by the number of linkages). The adjustment cost includes language acquisition and getting to know the new culture and manners of the new society. Information is assumed to be complete, i.e., when a new immigrant joins the society, he or she is aware of the links between the members of the group. One could also think of these costs as a function of the distance between the different members in the diaspora.

Individuals derive benefits from direct linkages, as well as from indirect linkages where only one intermediate person exists (the distance between the links is

\footnotetext{
${ }^{2}$ Jackson (2005) presents a comprehensive review of the vast emerging literature on network
} formation. 
limited to two people). ${ }^{3}$ In other words, an individual derives benefit from friends and "friends of friends". This is precisely the idea behind the diaspora network in which each person can benefit from the network, even if one is a friend of a friend. Clearly, the benefit from a direct link is higher than that from an indirect link. For example, when talking about trade between countries, personal linkages are much more beneficial. In addition, both agents benefit from the linkage, but the immigrant benefits more from the linkage with a native than the native does from the linkage with the immigrant. ${ }^{4}$ Moreover, the immigrant's benefit from a linkage with a native is higher than his or her benefit from a linkage with another immigrant. ${ }^{5}$ Note that the utility obtained by the migrants from the link is a function of their expected utilities as a function of the possible diaspora networks.

To state matters formally, let $M$ represent the migrant and $L$ the native such that:

$u_{M L}-$ the immigrant's utility from a direct link with a native

$v_{M L}-$ the immigrant's utility from an indirect link with a native

$u_{M M}-$ the immigrant's utility from a direct link with an immigrant

$v_{M M}-$ the immigrant's utility from an indirect link with an immigrant

$u_{L M}-$ the native's utility from a direct link with an immigrant

$v_{M L}-$ the native's utility from an indirect link with an immigrant.

As stated above, we assume that $u_{M L}>u_{L M}, u_{M L}>u_{M M}, u_{M L}>v_{M L}, u_{L M}>v_{L M}$ and $u_{M M}>v_{M M}$. Note that if an agent has both a direct and indirect link with the same agent, he or she gains from the direct link, but not from the indirect one.

It is assumed that the immigrants are homogeneous in terms of adjustment costs and benefits from ties. Further on in this section, we will present a discussion on how the results change if these assumptions do not hold.

\footnotetext{
${ }^{3}$ See, for example, Brueckner (2006).

${ }^{4}$ For example, the native can employ the immigrant. Then both employer and worker benefit from the linkage, but the benefit to the worker, who has found a job, is higher.

${ }^{5}$ The natives hold more information, job and accommodation options, business opportunities, stock market tips and higher product quality than the immigrants.
} 
We assume that the agent who benefits from the linkage more than his or her counterpart initiates the link and incurs the linking cost. ${ }^{6}$ Thus, we expect the immigrant to carry the adjustment cost as well as the variable linking cost. This immigrant has the burden of the linking cost as he or she invests in order to make the linkage work with the rest of the diaspora. The immigrants maximize their utility with regard to network formation. ${ }^{7}$ Denote the utility that the immigrant obtains from creating a linkage only with natives by $X . X$ contains $J(J>0)$ direct links with natives and $K(K \geq 0)$ indirect links with natives:

$$
X=J u_{M L}+K v_{M L}-J e-c
$$

Denote the utility of the immigrant from an indirect link with natives (which he or she receives by direct linkage with an immigrant who maintains a linkage with natives) by $Y$. This takes into consideration the expected benefits from the linkages with the rest of the diaspora. Note that $Y$ contains only the direct links of $X$, but not the indirect links, under the assumption that the distance between the links is limited to 2 . Thus,

$$
Y=J v_{M L}+u_{M M}-e
$$

Looking at Figure 1, the first immigrant $(M 1)$ derives benefit from one direct link and three indirect links. When the second immigrant creates a link only with the first immigrant, he or she benefits only from one indirect link with the native $(L 1){ }^{8}$

\footnotetext{
${ }^{6}$ This assumption is based on Bala and Goyal (2002a, 2002b). For example, if one individual hosts or phones the second, both have a time cost, but only one pays for the hospitality or the conversation.

${ }^{7}$ In section 3 we refer to the different possible interactions of the first immigrant with the natives.

${ }^{8}$ Our analysis deals with single migrants who make decisions; however, it can also be relevant for different cohorts or different waves of immigration, given that immigrants in each wave or cohort are homogeneous.
} 


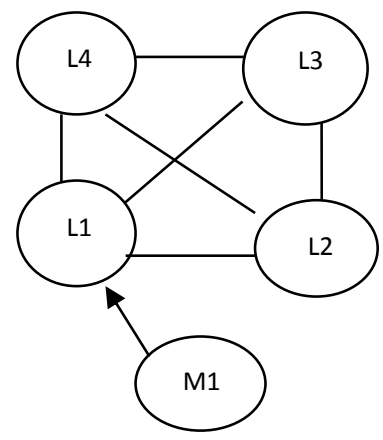

Figure 1

Following Berry (1997), assimilation takes place when the immigrant forms links with natives, but severs links with other immigrants. ${ }^{9}$ Separation (or segregation) occurs when the immigrant forms links with immigrants but not with natives. Note that the links with other immigrants may well be with other immigrants worldwide and not locally. Integration occurs when the immigrant interacts with both societies: immigrants and natives. This increases the possibility of international trade. Marginalization takes place when the immigrant fails to maintain an interaction with either society and thus, no international trade is achieved. ${ }^{10}$ The following table presents these four states:

\begin{tabular}{|l|c|c|}
\hline & Link to natives & Link to immigrants \\
\hline Assimilation & + & - \\
\hline Separation & - & + \\
\hline Integration & + & + \\
\hline Marginalization & - & - \\
\hline
\end{tabular}

${ }^{9}$ It should be noted that assimilation has a different meaning in the economic literature, i.e., the process whereby a minority adapts to the customs of the host society and acquires the local language. An additional meaning would be the process of closing the wage gap between immigrants and natives (see for example, Borjas, 2015).

${ }^{10}$ Constant et al. (2006) refer to these states as continuous variables which can have values between 0 and 1. For simplification, we refer to these states as dichotomous variables (creating a linkage or not). 
Let us now examine the possible types of network formation between natives and immigrants. The first immigrant faces two main possibilities: to form a link with the natives or not. Suppose that the first immigrant chooses the first possibility and forms a link with the natives. This choice reveals a positive net benefit which satisfies:

$$
X>0
$$

The second immigrant faces the following possibilities: (a) to form a link only with natives; (b) to form a link only with the first immigrant; (c) to form a link with natives and the first immigrant, or (d) not to form any links at all. From inequality (3) and the fact that the second immigrant can also adopt the choice of the first immigrant, possibility (d) is not worthwhile for the second immigrant.

Suppose that the second immigrant chooses the first possibility and forms a link only with natives. His or her benefit then satisfies:

$$
X+v_{M M}>Y
$$

and

$$
X+v_{M M}>X+u_{M M}-e
$$

From inequality (5), it follows that:

$$
v_{M M}>u_{M M}-e
$$


This means that the immigrant's benefit from an indirect link with another immigrant is greater than the net benefit from a direct link. Adding $(n-2) v_{M M}$ to both sides of inequality (4), we obtain:

$$
X+(N-1) v_{M M}>Y+(N-2) v_{M M}
$$

The LHS of inequality (7) represents the benefit gained by immigrant number $n(n>2)$ from a link with natives only, while the RHS of inequality (7) presents the benefit gained by immigrant number $N$ from a link with the first immigrant only. Inequalities (6) and (7) will be valid for all future immigrants. Hence, all subsequent immigrants will only form links with the natives and assimilation will be achieved. Figure 2 demonstrates this state.

In the case of assimilation, the immigrants identify strongly with the host culture and society, coupled with its norms, values, and codes of conduct, and identify only weakly with the source society. Thus, the benefit received by the source country from the diaspora is low, whereas the diaspora contributes to the host country. The immigrants can transfer, via their links, knowledge to the local people and increase innovation in the host country. This result is in line with Chellaraj et al. (2008) who examined the effect of foreign graduate students on US innovation. They found that these students have a significant and positive impact, with a $10 \%$ rise in the number of foreign graduate students increasing patent applications by $4.5 \%$, university patent grants by $6.8 \%$ and non-university patent grants by $5.0 \%$. Hornung (2008) also found evidence for a positive correlation between the share of the Huguenot diaspora in Prussia and productivity in textile manufacturing hundreds of years after their immigration. Kanas et al. (2012) showed that social contact with natives enables immigrants to reach a higher occupational status, increasing their ability to affect the host country's economy. 


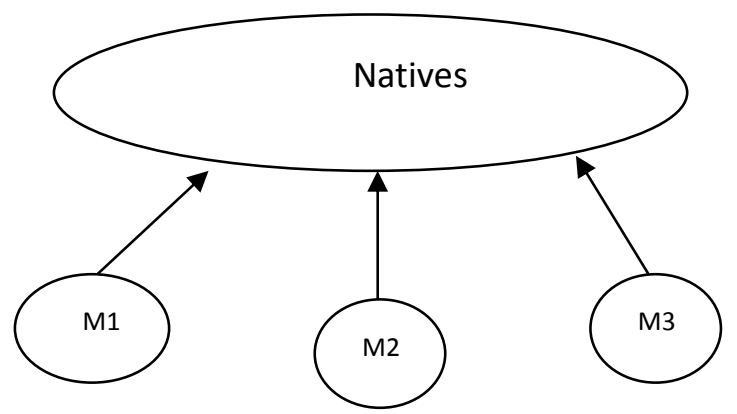

Figure 2

If the second immigrant chooses option (b), i.e. to form a link only with the first immigrant, his or her benefit will satisfy:

$$
Y>X+v_{M M}
$$

Adding $(n-2) v_{M M}$ to the both sides of inequality(8), we get:

$$
Y+(n-2) v_{M M}>X+(n-1) v_{M M}
$$

The LHS of inequality (9) presents the benefit of immigrant number $n(n>2)$ from a link with the first immigrant only, while the RHS of inequality (9) presents the benefit of immigrant number $N$ from a link with natives only. Inequality (9) will be valid for all subsequent immigrants and they will not create linkages with the natives. Note that if the second immigrant had immigrated first, he or she would have had to have been assimilated into the host country and to have acquired the local language. 


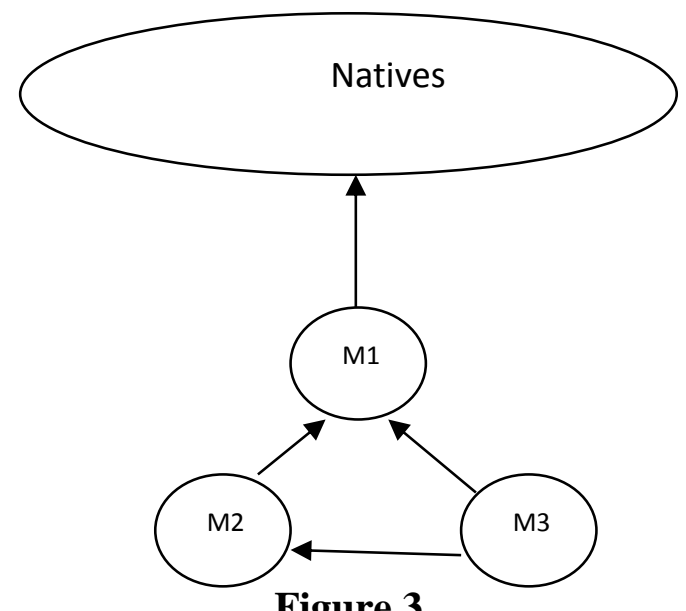

Figure 3

In this case, where the second immigrant chooses not to link with the natives, separation is obtained, i.e., two segregated groups are created: immigrants and natives. The unique interaction between these groups is via the first immigrant who serves as a "bridge" between the two societies. On the one hand, this decreases the cost of creating links with the natives, since it is easier to connect with a different immigrant than with a local. On the other, the diaspora network will depend on the linkage of one main migrant, which may increase the uncertainty of trade over time, as it is a function of one strong linkage. The first immigrant is the only agent who incurs the connection cost with the host society, but all of the following immigrants bear the linking cost with that first immigrant. One can think of this first immigrant as the leader/representative of the immigrants. As we will see further on, this immigrant's strength increases when the stock of the immigrants in the new country increases. Figure 3 presents a possible formation of this state.

A vast amount of economic literature has shown that as linguistic concentration (enclave) increases, language proficiency decreases. For example, Lazear (1999), basing his study on US census data, showed that when the proportion of immigrants in the host country increases, their incentive to learn about the new culture and acquire the new language decreases. Chiswick and Miller (2005) found that living in an area of linguistic concentration reduces an immigrant's English-language skills. Linguistic concentration uses the benefits and cost invested by the immigrant that has already connected to a native and thus enables using the already-made linkage to benefit the rest of the immigrants. Under "separation", the immigrants do not acquire the host country's language, and they therefore have less information about the labor market and trade possibilities, and fewer economic opportunities. In addition, the immigrants have no direct links with the natives. 
However, the immigrants continue to retain their ethnic identity, and therefore markets of ethnic goods will be developed. We expect the immigrants to exploit the group ties to develop international trade, mainly of ethnic goods and services, between the source country and the diaspora. The benefit granted by the natives in the diaspora (such as knowledge acquisition, access to distribution channels) is limited, occurring only via the first immigrants, whereas the source country will benefit from the increase in trade between different countries.

Battu et al. (2011) demonstrated this case of separation with a middleman between the immigrants and natives. They showed theoretically and empirically that less assimilated unemployed ethnic workers are more likely to use their friends and family as their main method of searching for a job. However, they have less chances of finding a job or a channel for international trade using this method than the assimilated unemployed ethnic workers who use formal job and network (international connections for trade) search methods (such as advertisements, employment agencies, responding to newspaper advertisements, etc.). If the second immigrant chooses option (c), i.e., to form a link with natives and the first immigrant then:

$$
X+u_{M M}-e>Y
$$

and

$$
X+u_{M M}-e>X+v_{M M}
$$

From inequality (11), it follows that:

$$
u_{M M}-e>v_{M M}
$$

Adding $(n-2)\left(u_{M M}-e\right)$ to both sides of inequality (10), we obtain: 


$$
X+(n-1)\left(u_{M M}-e\right)>Y+(n-2)\left(u_{M M}-e\right)
$$

Inequalities (12) and (13) will be valid for all of the subsequent immigrants. Thus, all of the immigrants will create linkages with natives as well as between themselves, and integration is obtained. Figure 4 demonstrates this case. This increases the cost but also the strength of the international diaspora trade, since the migrants are not relying on only one link.

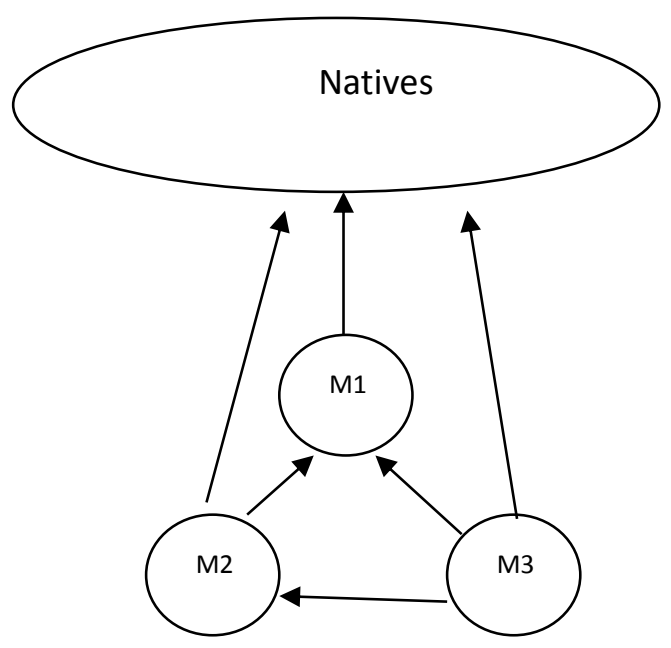

Figure 4

In the case of integration, the immigrant combines, incorporates, and exhibits both strong dedication to the country of origin and commitment to the host society. Thus, the natives, the migrants in the diaspora and the source country all benefit from the immigrants' ties. The immigrants provide information on, and access to distribution channels, and thus increase the international trade between countries. Nevertheless, this process will take time to establish, and trade may not develop until later in the process with a higher cost of creation.

We summarize the results in 


\section{Proposition 1:}

Where $X>0$, then:

- If $X+v_{M M}>Y$ and $v_{M M}>u_{M M}-e$, we obtain assimilation.

- If $X+v_{M M}>Y$ and $u_{M M}-e>v_{M M}$, we obtain integration.

- If $Y>X+v_{M M}$ we obtain separation (or segregation) with a middleman.

It should be noted that the strength of the first immigrant's connection with the natives plays an important role. As the first immigrant's links with the natives become stronger, the second immigrant's utility from indirect link $Y$, compared to his/her utility from a direct link with the natives, $X+v_{M M}$, increases. Thus, segregation with a middleman may be obtained. An additional parameter that also plays a major part in the results is the cultural distance between the host country and source country societies. As the cultural distance decreases, the adjustment cost, c, decreases and the net benefit for the immigrant from a relation with the natives, $\mathrm{X}$, increases. Thus assimilation and integration may be obtained.

Let us now examine the case in which the first immigrant does not create a link with the natives. His or her choice reveals:

$$
X<0
$$

Inequality (14) will be valid for all future immigrants, and they will therefore not create a link with the natives. The second immigrant faces the following possibilities: (a) to form a linkage only with the first immigrant, or (b) not to form any linkages at all. If the second immigrant chooses (a), then:

$$
u_{M M}-e>0
$$


The third immigrant can create a linkage with only one immigrant or can create a linkage with all previous immigrants. If he or she links with only one immigrant, then:

$$
v_{M M}>u_{M M}-e
$$

Inequalities (14) and (16) will be valid for all future immigrants, thus all immigrants will have linkages only via an intermediary: the first immigrant. ${ }^{11}$ The first immigrant is used as a "hub" for the immigrants' society as demonstrated in Figure 5.
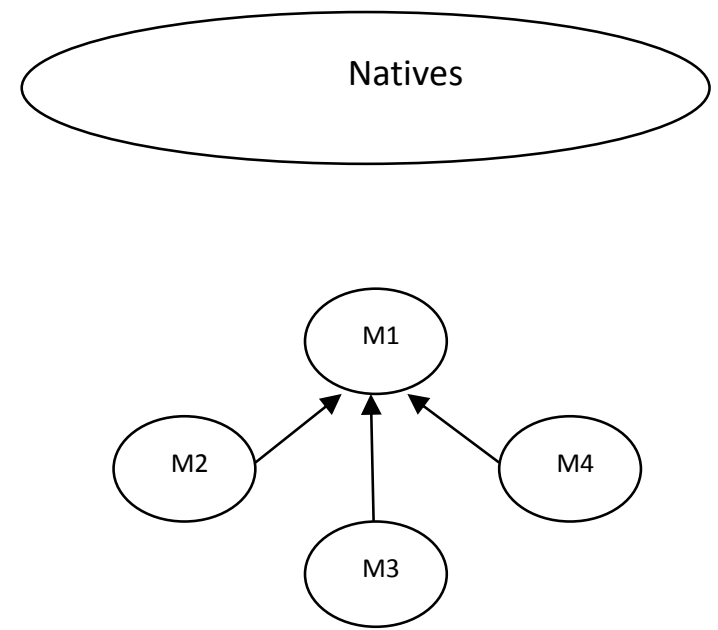

Figure 5

If the third immigrant creates links with both the first and second immigrant, then:

$$
u_{M M}-e>v_{M M}
$$

Inequalities (14) and (17) will be valid for all of the subsequent immigrants, thus all of them will create linkages among themselves, but not with the natives. ${ }^{12}$ With both

\footnotetext{
${ }^{11}$ The structure of this formation is called "star" network (Jackson, 2003).
} 
possibilities, the third immigrant's choice of "separation" is obtained. In contrast to the previous case in which there was separation, there is no middleman between the host and immigrant societies. There is no connection between the two societies at all, thus, the host society does not receive any benefit from the diaspora. However, as in "separation" with a middleman, the ethnic market (food, clothes, etc.) in the enclaves can be developed and the home country can receive a benefit from international trade with the diaspora.

Public policy with regard to resources allocated to the first immigrant(s) can affect this outcome by changing it to "separation with a middleman". As the immigrant's utility from a direct link with a native, $u_{M L}$, is higher, less public investment is required. Clearly, when the fixed adjustment cost, $c$, is higher, more resources are required. This can be obtained by proposing incentives for international trade between the different countries, such as subsidies tax incentives, etc.

If the second immigrant chooses option (b), i.e., does not form any links at all, then:

$$
u_{M M}-e<0
$$

Inequalities (14) and (18) will be valid for all future immigrants. These immigrants will have no interaction with the previous immigrants or the natives, and "marginalization" is obtained (see Figure 6). In this state, neither the host country nor the home country receive any benefit from the diaspora.

Note that the condition for this state (i.e., satisfying inequalities (14) and (18)) occurs when the cultural distance between the immigrants and the natives is very large and the utility of the immigrants from interaction with other immigrants is low. This result is in line with Constant et al. (2006), who found that Muslim immigrants are less integrated in Germany and more marginalized than Christian immigrants. Two-thirds of the native population is Christian, and therefore the Christian immigrants' adjustment costs are low. The financial status of the Muslim immigrants

\footnotetext{
${ }^{12}$ The structure of this formation is called "complete" network (Jackson, 2003).
} 
is low relative to that of the Christian immigrants. Thus, the benefit obtained by a Muslim immigrant from connecting to another Muslim immigrant is lower than that obtained by a Christian immigrant connecting to another Christian immigrant.

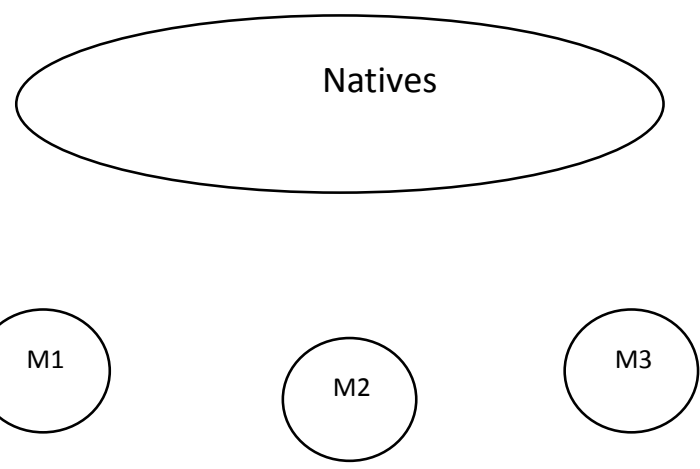

Figure 6

\section{Proposition 2:}

Where $X<0$, then:

- If $u_{M M}-e>0$, we obtain separation (or segregation) without a middleman.

- If $u_{M M}-e<0$, we obtain marginalization.

Separation without a middleman and marginalization negatively affect the immigrants' trade possibilities. There will be no ties, and the possibility of transferring information is low. This means that there will be a low level, if any, of international trade. There are two reasons for this: first, the immigrants do not acquire the host country's knowledge which is needed for trade, and thus cannot compete effectively in the host country for the possibility of trade between the countries. Second, the immigrants have no social contact with the natives who could give them access to the host country's market. It is clear that the immigrants' economic disadvantage under marginalization is greater than under separation without a middleman, because in the former state, the immigrants have no social ties at all. This lack of social contact prevents them from obtaining information or assistance in local markets. 
We assumed above that immigrant linkage with natives is more beneficial than linkage with another immigrant. The native is better informed regarding market and trade opportunities. Thus, it is expected that trade options between the different host countries and the home country under separation without a middleman will be lower than under separation with a middleman.

As noted earlier, we assumed that all of the immigrants are homogeneous in terms of emigration cost and the benefits that stem from linking to the local people. Let us discuss how the results change if these assumptions are relaxed. If the potential immigrants have different migration costs which depend on their personal characteristics (such as age, family status, social status, education, assets), then it is expected that the immigrants with the lower migration costs will immigrate first. As the stock of immigrants in the destination country increases, the migration cost decreases (see Carrington et al., 1996). Thus, immigrants with higher migration costs join the host country and benefit from positive externalities (created by the previous immigrants) which decrease the cost of migration. The immigrants with lower migration cost connect the local population to the diaspora. The immigrants can also be heterogeneous with regard to their benefit from international trade established between the natives and the diaspora (which stems from their ability to negotiate, risk ratios, preferences). If the immigrants that benefit little from international trade immigrate first, segregation without a middleman or marginalization may well occur (until the arrival of the immigrant who benefits highly from international trade). When the latter immigrant arrives in the destination country, he or she creates links with the natives. The immigrants who immigrated previously may create links with this immigrant and derive benefits from his/her relations with the natives (for example, in the labor market). The immigrant enjoying a high benefit from international trade becomes the diaspora leader. He or she creates links between the natives, the immigrants and the host country. In this case, a state of marginalization or separation without a middleman is not possible. 


\section{Who incurs the linking cost?}

As assumed above, the person who benefits most from the connection incurs the linking cost, $e$. Since $u_{M L}>u_{L M}$, the first immigrant bears the linking cost. Let us focus on the case of separation with a middleman. We distinguish between two situations: (a) the first immigrant creates linkages with only some of the natives, ${ }^{13}$ and (b) the first immigrant creates linkages with all of the natives.

In the first situation, the immigrant's benefit from an indirect link with a native is higher than the net benefit from a direct link, i.e.:

$$
v_{M L}>u_{M L}-e
$$

The natives who do not have a direct link with the immigrants (for example, L2, L3 and $L 4$ in Figure 1) benefit from indirect links with the first immigrant, $v_{L M}$. This satisfies:

$$
v_{L M}>u_{L M}-e
$$

Over time, the stock of immigrants in the diaspora, $n_{1}$, increases. When $n_{1}$ is high enough, the benefit from a direct link with the first immigrant, the middleman, for all natives can be equal to:

$$
u_{L M}+\left(n_{1}-1\right) v_{L M}-e \geq v_{L M}
$$

Thus, the natives who previously had no direct link with the immigrants create a direct link with the first immigrant and carry the linking costs. This is because the

\footnotetext{
${ }^{13}$ In this case, the first immigrant creates a link with the natives so that he or she can gain more indirect links through them.
} 
benefit is now sufficiently large, since the immigrants may have a sufficiently large diaspora network worldwide that can very much benefit the local individual.

\section{Proposition 3:}

When the stock of immigrants from the same origin in the diaspora is high enough, the natives, who previously had only an indirect link with the immigrant-the middleman-initiate a direct linkage with him or her.

As the diaspora increases, the local population will gain a higher benefit from the links with the migrants and the migrants' links in the diaspora, and will use the migrants and channels to increase international trade between the different countries. The diaspora itself will get stronger and may even create a diaspora leader. As the links increase and the diaspora increases in size and over more countries, the benefit of trade increases and linkages with the local population in each country will increase.

Following the creation of new links between the first immigrant and the natives, immigrants worldwide can benefit from indirect links with natives, when he or she (the first immigrant) previously had a direct link with them (for example, $L 1$ in Figure 1). As shown in inequality (19), the immigrant's benefit from an indirect link with a native is higher than the net benefit from a direct link, and therefore the first immigrant will cease to maintain a link with the natives and the natives' benefit will decrease to $v_{L M}$. From inequality (21), it follows that those natives prefer to create a direct link with the first immigrant and to increase their utility to $u_{L M}+\left(n_{1}-1\right) v_{L M}-e$ . The position of the first immigrant improves twice: first, by having more direct linkages than before, and second, because the linking cost shifts to the natives. Note that the utility of the subsequent immigrants from a direct link with the first immigrant, $Y$, increases to $(J+K) v_{M L}+u_{M M}-e$. Figure 7 demonstrates this: the indirect links between the first immigrant and the natives (i.e. L2, L3 and L4) become direct links, in addition to the existing direct link (i.e. $L 1$ ), where the natives incur the linking cost. 


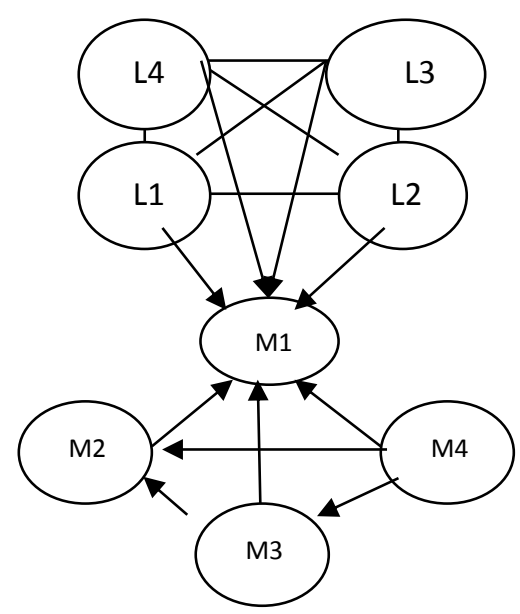

Figure 7

Let us examine the second case of separation with a middleman, in which the first immigrant creates linkages with all of the natives. In this case:

$$
u_{M L}-e>v_{M L}
$$

As previously, over time, the stock of immigrants in the host country, $n_{2}$, increases. When $n_{2}$ is high enough, the benefit to the natives from a direct link with the first immigrant — the middleman—satisfies:

$$
u_{L M}+\left(n_{2}-1\right) v_{L M}-e \geq u_{L M}-e
$$

Thus, from $n_{2}$ immigrants in the host country, the natives bear the linking cost instead of the immigrant. 


\section{Proposition 4:}

When the stock of immigrants worldwide (in the diaspora) is sufficiently high, only the natives bear the linking cost with the immigrants.

From inequalities (20), (21) and (23), we conclude that:

$$
u_{L M}+\left(n_{1}-1\right) v_{L M}-e>u_{L M}+\left(n_{2}-1\right) v_{L M}-e
$$

From inequality (24), it follows that:

$$
n_{1}>n_{2}
$$

\section{Proposition 5:}

When the first immigrant has direct links with all of the natives, less immigrants are required to reach the mass number which will cause the natives to bear the linking costs (in comparison to the case in which the first immigrant has direct links with some of the natives).

It should be noted that moving from the case in which the immigrant bears the linking costs to the case in which the natives bear those costs does not depend on the size of the native group; it does, however, depend on the size of the immigrant group in the diaspora. This is because the number of immigrants in the diaspora increases (worldwide) the benefit from an increase in trade worldwide and the migrants are the link between the different countries.

\section{Discussion}

We present a theoretical model of network formation when a sequence of homogeneous individual immigrants with the same background emigrate to different 
countries in the world - the diaspora. When the immigrant forms a link with the natives worldwide, he or she incurs adjustment costs, in addition to the variable linking costs such as language acquisition and getting to know local customs and the new culture. The agents (immigrant and native) benefit from the linkage via the possibility of international trade with all countries in which the immigrants are present. However, at least in the first stages, the benefit to the immigrant can be higher than that for the local population.

Using Berry's (1997) approach, we found the conditions for the different types of network formation: assimilation, integration, separation and marginalization. We distinguished between two levels of separation: separation with a middleman and separation without one. We found that the behaviors of the first two immigrants (in each country) determine the type of network that will form. The result depends on the cultural distance between the host country and the home country (as a representative of the culture of migrants from the same origin worldwide), as well as on the gap between the immigrant's benefit from direct linkage vs. indirect linkage with natives.

In theory, it is the first two immigrants who determine the final outcome. ${ }^{14}$ In reality, it may not be the first two immigrants but those that immigrated first or the two first migration waves/cohorts. Our results indicate that the policy-maker can affect the type of network formed by allocating resources to the first immigrants' assimilation, i.e., by investing early in assimilation. Assimilation of the first immigrants can prevent formation of the severe states of separation without a middleman and marginalization. Moreover, they can approve subsidies and tax reductions for international trade. The type of network formed (assimilation, integration, separation or marginalization) affects the level of, and benefits from international trade worldwide, as well as the composition of the imported products. For example, under segregation, the share of ethnic goods is higher than in the other states.

\footnotetext{
${ }^{14}$ For a similar type of a result regarding the effect the first two individuals on the rest of the decision makers see Banerjee (1992) and with regard to the effect the first two migrants have on the decisions of the following migrants (with regard to informational cascades and migration), see Epstein (2008, 2010).
} 
We also showed how immigrant leadership, which serves as a middleman between the immigrants and the natives, is established. We find that the strength of this leadership increases over time. As more immigrants from the same origin become established all over the world, new linkages from all over the world are created with the first immigrant, increasing the possibilities for global trade. The natives are aware of this advantage of the diaspora of immigrants from the same origin, and they know the benefits of linking up with the migrants' local representatives; they will therefore be willing to incur the cost of linking to increase their chances of using the benefits of the global migrant network to increase income via trade.

From our model, it also follows that under separation without a middleman, the endogenous migration decision will increase immigrant flow worldwide. As the number of immigrants from the same origin increases, the future immigrant can benefit from more indirect links via one direct linkage. A diaspora of immigrants from the same origin will increase international trade and will benefit the migrants and the local populations in the different countries. 


\section{References}

Bala, V. and Goyal, S. (2000a), "A noncooperative model of network formation", Econometrica, Vol. 68 No. 5, pp. 1181-1229.

Bala, V. and Goyal, S. (2000b), "A strategic analysis of network reliability", Review of Economic Design, Vol. 5, pp. 205-228.Bartel, A.P. (1989), "Where do the new U.S. immigrants live?” Journal of Labor Economics, Vol. 7 No. 4, pp. 371-391.

Battu, H., Seaman, P. and Zenou, Y. (2011), "Job contact networks and the ethnic minorities", Labour Economics, Vol. 18 No. 1, pp. 48-56.

Bauer, T., Epstein, G.S. and Gang, I.N. (2005), "Enclaves, language and the location choice of migrants", Journal of Population Economics, Vol. 18 No. 4, pp. 649-662.

Bauer, T., Epstein, G.S. and Gang, I.N. (2007), "The influence of stocks and flows on migrants' location choices", Research in Labor Economics, Vol. 26, pp. 199-229.

Beine, M., Docquier, F. and Özden, Ç. (2011), "Diasporas", Journal of Development Economics, Vol. 95 No. 1, pp. 30-41.

Berry, J.W. (1997), "Immigration, acculturation and adaptation”, Applied Psychology, Vol. 46 No. 1, pp. 5-34.

Blanes, J.V. (2005), "Does immigration help to explain intra-industry trade? Evidence for Spain", Review of World Economics, Vol. 141 No. 2, pp. 244-270.

Bodomo, A. (2013), "African diaspora remittances are better than foreign aid funds", World Economics, Vol. 14 No. 4, pp. 21-29.

Borjas, G.J. (2000), "Ethnic enclaves and assimilation", Swedish Economy Policy Review, Vol. 7, pp. 89-122.

Borjas, G.J. (2015), "The slowdown in the economic assimilation of immigrants: aging and cohort effects revisited again", Journal of Human Capital, forthcoming.

Brueckner, J.K. (2006), "Friendship networks", Journal of Regional Science, Vol. 46 No. 5, pp. 847-865.

Carrington, W.J., Detragiache, E. and Vishwanath, T. (1996), "Migration with endogenous moving costs", The American Economic Review, Vol. 86 No. 4, pp. 909-930.Casella, A. and Rauch, J.E. (2002), "Anonymous market and group ties in international trade", Journal of International Economics, Vol. 58 No. 1, pp. 19-47.

Chellaraj, G., Maskus, K.E. and Mattoo, A. (2008), "The contribution of international graduate students to US innovation", Review of International Economics, Vol. 16 No. 3, pp. 444-462.

Chiswick, B.R. (1978), "The effect of Americanization on earning of foreign-born men", Journal of Political Economy, Vol. 86, pp. 897-921. 
Chiswick, B.R. and Miller, P.M. (2005), "Do enclaves matter in immigrant adjustment?" City and Community, Vol. 4 No. 1, pp. 5-35.

Comola, M. and Mendola, M. (2015), "Formation of migrant networks", The Scandinavian Journal of Economics, Vol. 117 No. 2, pp. 592-618.

Constant, A. and Zimmerman, K.F. (2009), "Work and money: payoffs by ethnic identity and gender", Research in Labor Economics, Vol. 29, pp. 3-30.

Constant, A. and Zimmermann, K.F. (2013), "Immigrants, ethnic identities and the nation-state", in Constant, A. and Zimmermann, K.F. (Eds.), International Handbook on the Economics of Migration, Edward Elgar, Cheltenham, UK and Northampton, USA, pp. 259-275.

Constant, A., Gataullina, L. and Zimmerman, K.F. (2009), "Ethnosizing immigrants", Journal of Economic Behavior and Organization, Vol. 69 No. 3, pp. 274-287.

Constant, A., Gataullina, L., Zimmerman, K.F. and Zimmerman, L. (2006), "Clash of cultures: Muslims and Christians in the ethnosizing process", IZA Working Paper No. 2350, IZA, Bonn, Germany.

Culter, D.M and Gleaser, E.L. (1997), “Are ghettos good or bad?” Quarterly Journal of Economics, Vol. 112 No. 3, pp. 827-872.

Dustmann, C. and Preston, I. (2007), "Racial and economic factor in attitudes to immigration", The B.E. Journal of Economic Analysis \& Policy, Vol. 7 No. 1, Article 62.

Epstein, G.S. (2008) "Herd and Network Effects in Migration Decision-Making", Journal of Ethnic and Migration Studies, 34(4), 567 - 583.

Epstein, G.S. (2010), "Informational Cascades and the Decision to Migrate" in Gil S. Epstein, and Ira N. Gang, (Eds), Migration and Culture: Frontiers of Economics and Globalization, volume 8, , Emerald Group Publishing Limited.

Epstein, G.S. (2013), "Issues on the political economy of migration", in Constant, A. and Zimmermann, K.F. (Eds.), International Handbook on the Economics of Migration, Edward Elgar, Cheltenham, UK and Northampton, USA, pp. 411-431.

Epstein, G.S. and Gang, I.N. (2010), "Migration and culture", in Beladi, H. and Kwan Choi, E. (Eds.), Frontiers of Economics and Globalization, Vol. 8. Emerald, UK, North America.

Epstein, G.S. and Heizler (Cohen), O. (2009), "Network formations among immigrants and natives", IZA Working Paper No.4234, IZA, Bonn, Germany.

Hercowitz, Z., and Pines, D. (1997), "Migration between home country and diaspora: an economic analysis", Journal of Public Economics, Vol. 65 No. 1, pp. 45-59.

Hornung, E. (2014), "Immigration and the diffusion of technology: the Huguenot diaspora in Prussia", The American Economic Review, Vol. 104 No. 1, pp. 84-122. 
Jackson, M. O. (2005), "A survey of network formation models: stability and efficiency", Group Formation in Economics: Networks, Clubs, and Coalitions, 1149

Kanas, A., Chiswick, B.R., van der Lippe, T. and Tubergen, F. (2012), "Social contacts and the economic performance of immigrants: a panel study of immigrants in Germany", International Migration Review, Vol. 46 No. 3, pp. 680709 .

Kugler, M. and Rapoport, H. (2007), "International labor and capital flows: complements or substitutes?" Economics Letters, Vol. 94 No. 2, pp. 155-162.

Lazear, P.E. (1999), “Culture and language”, Journal of Political Economy, Vol. 1074 No. 6, pp. 95-126.

Naghavi, A. and Strozzi, C. (2015), "Intellectual property rights, diasporas, and domestic innovation", Journal of International Economics, Vol. 96 No. 1, pp. 150161.

Plaza, S. (2013), "Diaspora resources and policies", in Constant, A. and Zimmermann, K.F. (Eds.), International Handbook on the Economics of Migration, Edward Elgar, Cheltenham, UK and Northampton, USA, 505-529.

Rauch, J.E. (2001), "Business and social networks in international trade", Journal of Economic Literature, Vol. 39 No. 4, pp. 1177-1203.

Tchouassi, G. and Sikod, F. (2010), "Altruistic preferences as motivation for migrants in the diaspora to remit to home communities", Research in Applied Economics, Vol. 2 No. 1. 